\title{
LrôNTING \\ PERANCANGAN \\ MUSEUM VAN DER PIJL DI BANJARBARU
}

\begin{abstract}
Ahmad Arifudin
Program Studi Teknik Arsitektur Fakultas Teknik Universitas Lambung Mangkurat 1610812310002@mhs.ulm.ac.id
\end{abstract}

\section{Naimatul Aufa}

Program Studi Teknik Arsitektur Fakultas Teknik Universitas Lambung Mangkurat naimatulaufa@ulm.ac.id

\begin{abstract}
ABSTRAK
Kota Banjarbaru memiliki salah satu tokoh penting dalam proses pembangunan daerah, yaitu Van der Pijl. Beliau adalah seorang arsitek keturunan Belanda yang merancang master plan Kota Banjarbaru dan beberapa bangunan pemerintah yang sampai saat ini sebagian besarnya masih digunakan. Peran Van der Pijl dalam proses pembangunan Kota Banjarbaru sangatlah penting, tetapi saat ini banyak masyarakat tidak mengetahui perkembangan kota Banjarbaru (awal ditemukan) terlebih tentang sosok Van der Pijl itu sendiri. Sehingga perlu adanya wadah untuk mengenalkan kembali dan memberikan pemahaman tentang Van der Pijl dalam proses pembangunan Kota Banjarbaru.
\end{abstract}

Kata kunci: Museum, Kota Banjarbaru, Naratif, Van der Pijl

\section{ABSTRACT}

The City of Banjarbaru has one of the important figures in the process of regional development, namely Van der Pijl. He was a Dutch architect who designed a master plan of Banjarbaru city and several government buildings that until today were still in use. Van der Pijl role in the construction of Banjarbaru city is very important, but nowadays many people do not know the development of the city of Banjarbaru (early found) about the figure of Van der Pijl itself. So the need for a container to reintroduce and give an understanding of Van der Pijl in the process of building Banjarbaru city.

Keywords: The Library, Rantau City, Learning.

\section{PENDAHULUAN}

Banjarbaru merupakah salah satu kota di indonesia yang memiliki gaya arsitektur Belanda, tidak hanya Kota Banjarbaru tetapi ada beberapa kota lain di Indonesia dengan gaya arsitektur Belanda diantaranya Surabaya, Jakarta, Yogyakarta, Semarang, Malang, Palembang, Kediri, Solo dan Medan. Berbeda dengan kota-kota tersebut, yang disebut dengan arsitektur gaya Belanda di Kota Banjarbaru adalah arsitektur yang dilahirkan setelah Indonesia 
Merdeka (1950 an), yang dirancang oleh Van der Pijl.

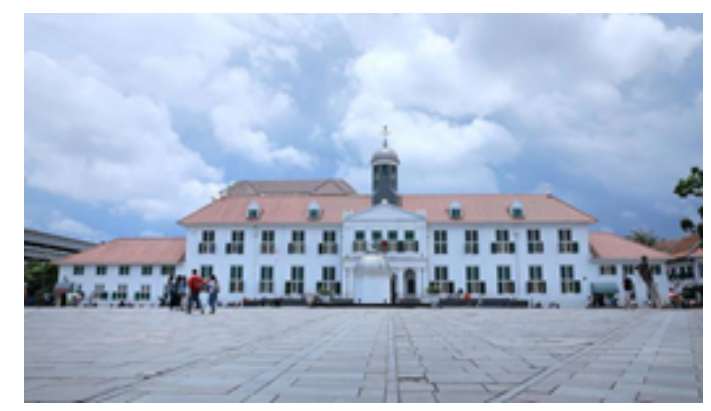

Gambar 1. Kota tua jakarta dengan gaya arsitektur belanda

Sumber : https://cdn1-production-images-kly

Banjarbaru merupakan hasil rancangan dari arsitek Belanda bernama Ir. D A W Van der Pijl, sehingga saat ini Kota Banjarbaru memiliki peninggalan bangunan-bangunan bersejarah bergaya arsitektur Belanda, menurut Huzairin dalam buku "tipologi dan morfologi arsitektur kolonial di Banjarbaru" terdapat 10 bangunan kolonial yang diteliti dari 20 bangunan adapun bangunan tersebut diantaranya :

1. Pemerintah Kota Banjarbaru

2. SMK-PP Negeri Banjarbaru

3. Dinas Pertanian Pemerintah Provinsi Kalimantan Selatan

4. Dinas Peternakan Pemerintah Provinsi Kalimantan Selatan

5. Koperasi Pemerintah Kabupaten Banjar, Dinas Perindustrian dan Perdagangan

6. Koperasi Pemerintah Kota Banjarbaru (bagunan utama), Dinas Perindustrian, Penanaman Modal dan Perdagangan

7. Koperasi Pemerintah Kota Banjarbaru (bagunan pendukung), dinas Perindustrian, Penanaman Modal dan Perdagangan

8. Dinas Pendidikan Pemerintah Kota Banjarbaru

9. Dinas Perhubungan Pemerintah Kabupaten Banjar Rumah
10. Dinas Kejaksaan Tinggi Pemerintah Kabupaten Banjar

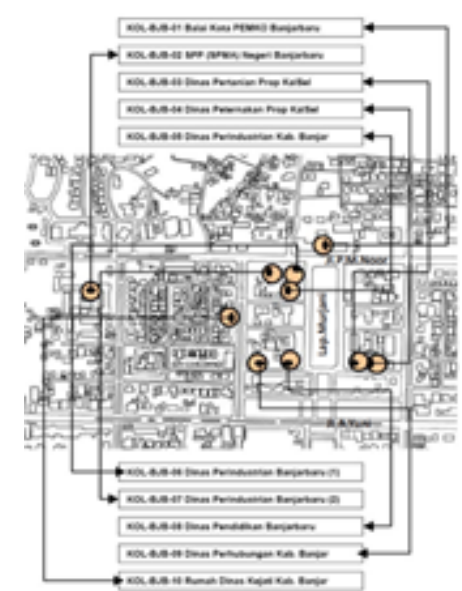

Gambar 2. lokasi sebaran sampel bangunan kolonial di Banjarbaru

Sumber : Buku tipologi dan morfologi arsitektur kolonial belanda di banjarbaru

Arsitektur kolonial belanda di Banjarbaru memiliki ciri khusus yang yang berbeda hal ini dikarenakan adanya penyesuaian terhadap iklim di Kalimantan Selatan yang tergolong tropis. Salah satu hal sederhana yang dilakukan oleh Van der Pijl terhadap rancangan bangunannya adalah penggunaan overstek yang panjang untuk menciptakan pembayangan di dalam bangunan. Penggunaan overstek panjang dinilai mampu mengurangi paparan sinar matahari ke dalam bangunan

Berdasarkan hasil wawancara (19 Februari 2020 pukul 16:43 WITA) dengan Bapak Rico Yusuf Hasyim salah satu orang yang peduli dengan karya van der pijl di kota banjarbaru sekaligus sebagai Ketua Yayasan SMK YPK bahwa saat ini karya-karya rancangan Van der Pijl tidak diarsip dengan baik, sehingga informasi mengenai karya beliau saat ini tidak bisa didapatkan secara menyeluruh, padahal karya-karya tersebut sering dicari peneliti dan jurnalis yang ingin mendokumentasikan karya Van der Pijl yang selanjutnya untuk 
dipublikasikan dalam media cetak sebagai bahan informasi masyarakat.

Berdasarkan wawancara (21 februari 2020 pukul 09:00 WITA) dengan kepala bidang kearsipan dinas arsip dan Perpustakaan Banjarbaru bapak Muhammad Nahwani, S. Sos, MM diinformasikan bahwa saat ini informasi terkait Van der Pijl dan kayaknya sangat sangat minim. Hal tersebut dikarenakan arsip dari pihak keluarga dan kolega Van der Pijl belum diperoleh pihak pemerintah kota, sehingga benda koleksi dan arsip terkait Van der Pijl tidak terarsip maksimal.

\section{PERMASALAHAN}

Berdasarkan latar belakang dan tujuan desain didapatkan permasalahan arsitektural sebagai berikut :

Bagaimana rancangan museum Van der Pijl di Banjarbaru yang mampu membuat pengunjung memahami tentang sejarah Kota Banjarbaru dan mengenal peran Van der Pijl dalam proses pembangunannya?

\section{TINJAUAN PUSTAKA}

\section{A. Tinjauan Museum}

1. Definisi Museum

Museum merupakan wadah untuk memelihara, menelaah, dan memamerkan barang-barang yang memiliki nilai lestari, contohnya, peninggalan sejarah, ilmu dan seni.

\section{Jenis Museum}

Macam-macam museum berdasarkan buku pedoman pendirian museum (1999), dapat dijadikan sebagai berikut :

a. Museum berdasarkan Koleksi

b. Museum berdasarkan kedudukan

c. Museum berdasarkan penyelenggara

d. Museum berdasarkan kriteria

\section{B. Tinjauan Sejarah Van der Pijl}

Van der Pijl merupakan seorang arsitek lulusan Universitas Leiden dengan keahlian khusus dibidang desain bangunan.

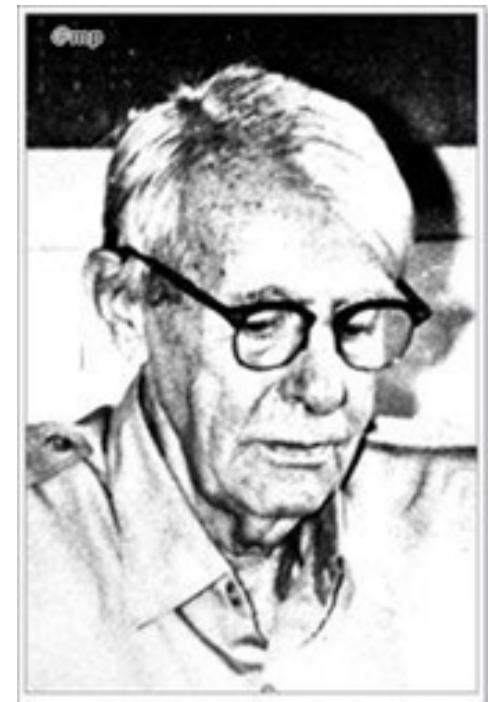

Gambar 3. Van der Pijl

Sumber : http://banjaristi.blogspot.com

Van der Pijl menerima gelar tekniknya di tiga agensi, yang pertama pada tahun (1920) prof, ex c. i, berikutnya di tahun (1922) cand. C. I dan Examen Architect di tahun (1924). Van der Pijl mengawali profesi sebagai seorang arsitek pada tahun 1924 hingga 1961. Pada tahun 1924 Van der Pijl pindah ke Indonesia. Adapun pengalaman profesional Van der Pijl di bidang arsitek sebagai berikut :

$\rightarrow$ Pada tahun 1924 hingga 1929, beliau bekerja sebagai seorang arsitek Partikulir di Kota Den Haag

$\rightarrow$ Pada tahun 1929 hingga 1930, beliau bekerja menjadi arsitek di biro insinyur Brinkman \& Voorhoeve Bandung

$\rightarrow$ Pada tahun 1930 hingga 1935 beliau menjadi arsitek kotamadya Cirebon

$\rightarrow$ Pada tahun 1946 hingga 1947 menjadi salah satu karyawan di biro 
planning prijzen dan statistik dari kementerian Wederopbouw en Volkshuisvesting s'Gravenhage

$\rightarrow$ Pada tahun 1947 hingga 1952 M. T. kl I Departemen V \& w (Wederopbouw dienst) menjadi salah satu bagian di Hoofd Residentie Waterstaat Kalimantan timur (Balikpapan)

$\rightarrow$ Pada tahun 1952 hingga 1957 seorang Insinyur Departemen Pekerjaan Umum ditugaskan untuk bergabung pada Provinsi Kalimantan Selatan (Kepala Bagian Gedung dan Pelaksana/Perencana Kota Banjarbaru)

$\rightarrow$ Pada Tahun 1957 hingga 1960 menjadi salah satu pegawai tinggi DPU dan ditugaskan di Provinsi Kalimantan tengah (Kepala Bagian Gedung dan Pelaksana/perencana Kota Palangka Raya)

$\rightarrow$ Pada tahun 1961 beliau Pensiun

$\rightarrow$ Pada tahun 1961 hingga 1968 Menjadi Guru di SMA (IImu Gaya dan IImu Pasti) dan direksi atau Supervisor, bangunan K. D. Tel, K.D Pos dan Mekatani Ujung.

Van der Pijl meninggal dunia pada tanggal 27 September 1974 dan dimakamkan di Kota Banjarbaru. Istrinya Van der Pijl bernama Anna Gaspers meninggal pada tanggal 27 Desember 1994 dan dimakamkan di Kota Banjarbaru.

\section{Tinjauan Arsitektural}

1. Standar jarak pandang

Standar jarak pengunjung terhadap objek lukisan menurut Julius Panero, dalam buku yang berjudul Dimensi Manusia dan Ruang Interior (2003), menyebutkan sebagai berikut :

Tabel 1. Standar Jarak Pandang Pengunjung

\begin{tabular}{|r|c|c|c|}
\hline No. & Pengunjung & $\begin{array}{c}\text { Tinggi Rata- } \\
\text { Rata }\end{array}$ & $\begin{array}{c}\text { Tinggi Rata-Rata } \\
\text { Jarak Pandang }\end{array}$ \\
\hline 1. & Pria & 165 & 160 \\
\hline 2. & wanita & 160 & 155 \\
\hline 3. & Anak-anak & 115 & 110 \\
\hline
\end{tabular}

Sumber : Dimensi Manusia dan Ruang Interior, Julius Panero, 2003

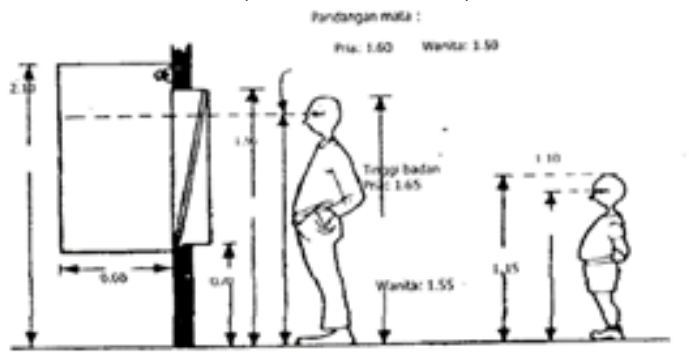

Gambar 4. Standar Jarak Pandang Manusia Sumber : Dimensi Manusia daN Ruang Interior, Julius Panero, 2003

\section{Standar Ruang Pamer}

Standar luas ruang untuk pajangan berdasarkan standar yang dikemukakan oleh Ernst Neufert (1997), adalah sebagai berikut :

Tabel 2. Standar Luas Objek Pamer Museum

\begin{tabular}{|c|c|c|}
\hline No. & Ruang Yang Dibutuhkan & Objek Pamer \\
\hline 1. & Lukisan & $3-5 \mathrm{~m} 2$ luas dinding \\
\hline 2. & patung & $6-10 \mathrm{~m} 2$ luas lantai \\
\hline 3. & $\begin{array}{c}\text { Benda-benda kecil } / 400 \\
\text { keping }\end{array}$ & $\begin{array}{c}1 \mathrm{~m} 2 \text { ruang lemari } \\
\text { kabinet }\end{array}$ \\
\hline
\end{tabular}

Sumber : Ernst Neufert, 1997, Hal. 135

\section{Sirkulasi Dalam Ruang Pamer}

Sirkulasi dalam ruang pamer terbagi menjadi 2 tipe yaitu sebagai berikut :

a. Tipe Primer

Tipe sirkulasi pengunjung dalam menikmati obyek pamer dalam ruang maupun antar ruang pamer.

b. Tipe Sekunder

Tipe sirkulasi yang mampu menunjang objek yang dilewatinya dapat dimengerti oleh pengunjung. 


\section{Tinjauan Konsep}

pada Pada perancangan museum van der pijl di banjarbaru akan menerapkan 3 konsep dasar diantaranya sebagai berikut :

\section{Heritage}

Heritage merupakan sesuatu yang diturunkan dari generasi ke generasi karena mempunyai nilai yang patut dipertahankan atau dilestarikan keberadaannya.

\section{Reminisce}

Reminisce dalam bahasa Indonesia yang artinya bernostalgia, mengingat, mengenang. Dalam konteks ini reminisce diartikan mengenang suasana yang mampu membawa pengunjung bernostalgia pada suatu kenangan bersejarah.

\section{Recreation and Education}

Recreation atau biasa disebut rekreasi adalah kegiatan yang dilakukan untuk mendapatkan kepuasan dan kesenangan. sedangkan Education atau edukasi merupakan salah satu pendidikan atau pembelajaran formal dan informal, pengetahuan dan keterampilan yang telah diwariskan dari generasi ke generasi.

Adapun konsep yang digunakan pada perancangan ini adalah "Reminiscent" yang artinya mengenang akan sejarah Van der Pijl dan pembangunan kota banjarbaru.

\section{PEMBAHASAN}

\section{A. Lokasi}

Tapak berada di Jl. Ahmad Yani Km 34 Loktabat Utara, Kec. Landasan Ulin, Kota Banjarbaru, Kalimantan Selatan 70714 (seberang Hotel Permata In). Lokasi perancangan berada di jalan poros utama yang menghubungkan Kota Banjarmasin dan Kota Banjarbaru. Lokasi juga berbatasan dengan Pemukiman warga serta beberapa bangunan komersil dan fasilitas umum yang mampu menunjang rancangan bangunan museum Van der Pijl. Titik koordinat lokasi : $3^{\circ} 26^{\prime} 30.8^{\prime \prime S}$ $114^{\circ} 49^{\prime 2} 28.3^{\prime \prime} \mathrm{E}$ berikut batasan-batasan pada lokasi tapak :

1. Utara : Perumahan warga dan lahan kosong

2. Selatan : Hotel Permata In dan Kantor Pajak Banjarbaru

3. Barat: Perumahan warga

4. Timur: Perumahan warga dan lahan kosong

Berdasarkan hasil survey, didapatkan batasan dan fasilitas penunjang pada tapak sebagai berikut :

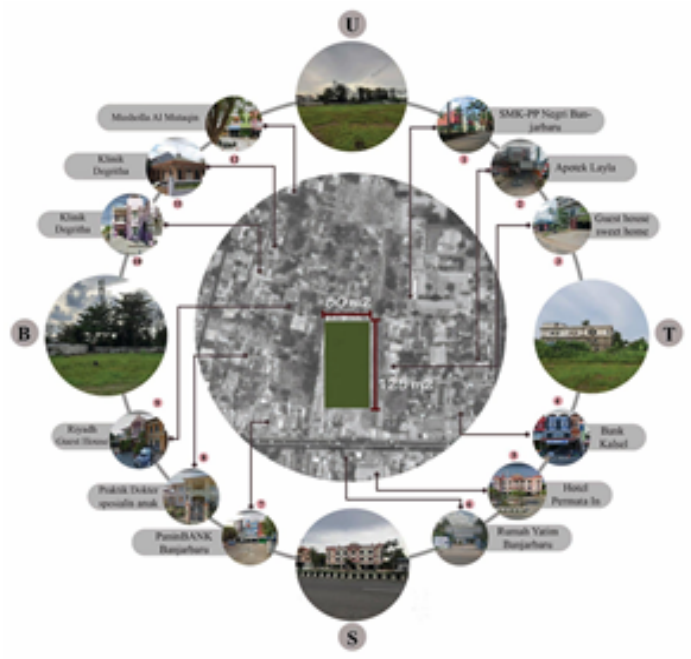

Gambar 5. Batas Tapak dan Fasilitas Penunjang Sumber : Penulis

\section{B. Konsep Rancangan}

\section{Konsep Program}

Konsep program yang akan digunakan pada perancangan museum Van der Pijl di Banjarbaru adalah "Reminiscent" yang artinya mengenang akan sejarah Van der Pijl dan pembangunan kota Banjarbaru. Reminiscent adalah sebuah konsep yang diterapkan dalam perancangan museum ini dengan menggunakan metode arsitektur naratif sebagai konsep perancangan dalam menguraikan cerita. 


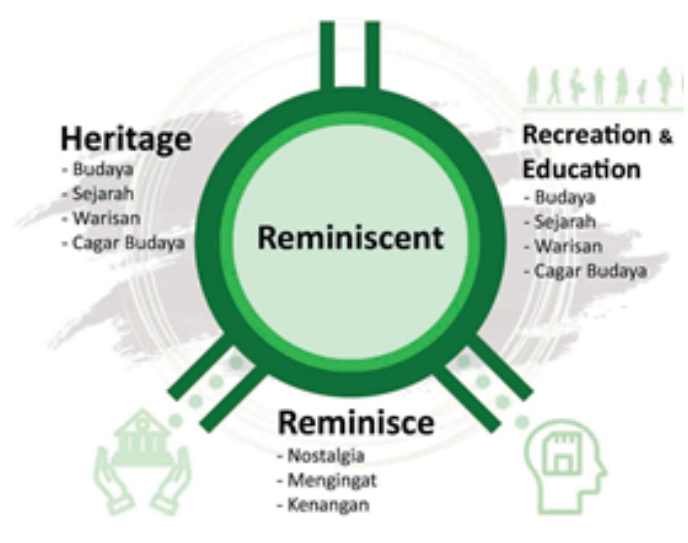

Gambar 6. Konsep Program Sumber : Penulis

2. Konsep Tatanan Zonasi

a. Konsep Tatanan Massa Dan Zonasi

Pengelompokkan zonasi pada perancangan ini dibagi berdasarkan lantai, dimana tiap lantai memiliki zonasi dan fungsi yang berbeda-beda. Adapun penjabaran pembagian zonasi dijelaskan pada skema berikut ini :

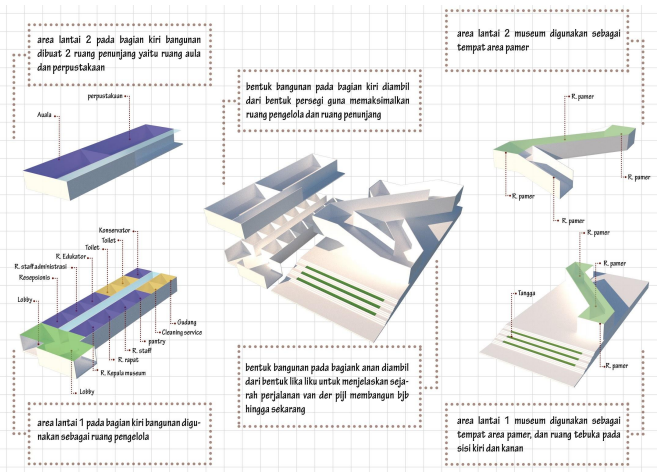

Gambar 7. Tatanan Zonasi

Sumber : Penulis

\section{b. Zonasi Lantai 1 Pengelola}

Zona lantai 1 secara umum bersifat private, karena kegiatan yang berlangsung dilakukan oleh staf dan pengelola.

- ruang pengelola diletakkan pada lantai 1 , dimana lantai 1 memiliki ruang yang bersifat semi publik sehingga tidak mengganggu untuk pegawai staf.
- Ruang service diletakan pada lantai 1 untuk mempermudah distribusi, dan tidak mengganggu pengunjung.

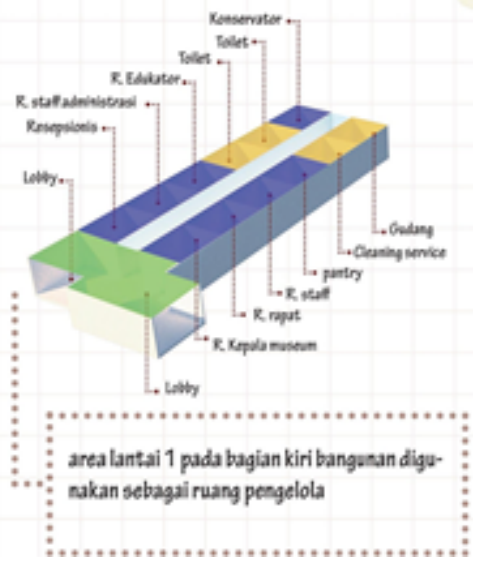

Gambar 8. Zonasi Lantai 1 Pengelola Sumber : Penulis

c. Zonasi Lantai 2 Ruang Penunjang

Pada zona lantai dua bersifat publik karena berfungsi sebagai penerima pengunjung.

- aula diletakkan pada lantai 2 guna memudahkan akses bagi pengunjung untuk menggunakan ruang aula.

- perpustakaan diletakkan pada lantai 2 guna memudahkan akses bagi pengunjung untuk menuju perpustakaan.

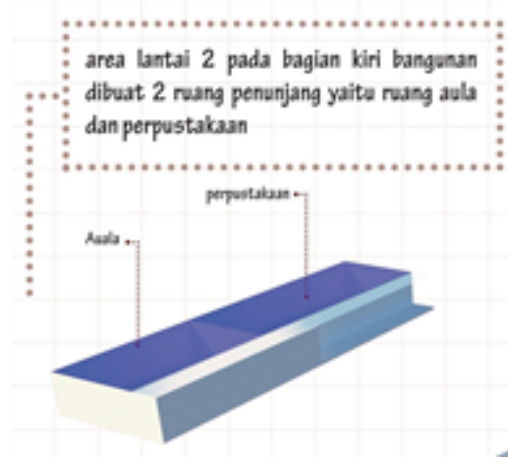

Gambar 9. Zonasi Lantai 2 Pengelola Sumber : Penulis

d. Zonasi Lantai 1 Museum

Zonasi lantai 1 berfungsi sebagai zona aktivitas outdoor yang terhubung langsung dengan bagian dalam bangunan, pada 
bagian selasar terhubung langsung dengan zona pamer museum.

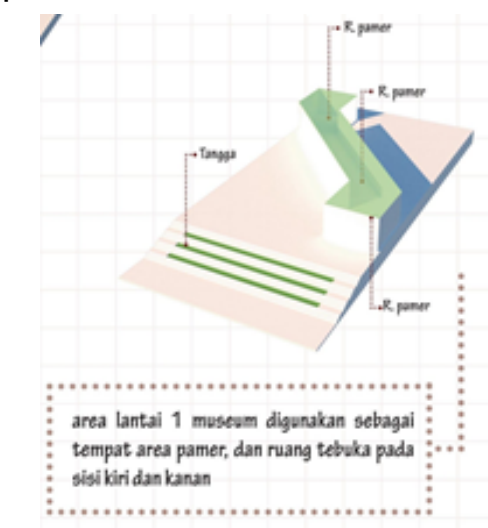

Gambar 10. Zonasi Lantai 1 Museum Sumber : Penulis

e. Zona Lantai 2 Museum

Pada zonasi lantai 2 museum berfungsi sebagai ruang pamer yang dihubungkan dengan sirkulasi berupa ramp dan tangga.

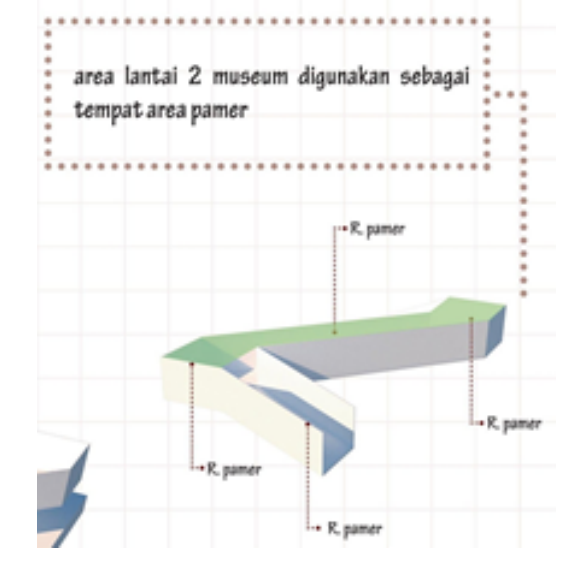

Gambar 11. Zonasi Lantai 2 Museum Sumber : penulis

\section{Konsep Sirkulasi}

Sistem sirkulasi Yang digunakan pada perancangan musem Van der Pijl yaitu sistem sirkulasi linier, hal ini bertujuan untuk mengarahkan gerakan pengunjung agar mereka dapat dengan mudah menemukan objek pamer, sehingga informasi dari setiap objek pamer dapat diterima oleh pengunjung sesuai dengan alur cerita atau sejarah. Adapun sirkulasi tiap lantai sebagai berikut :

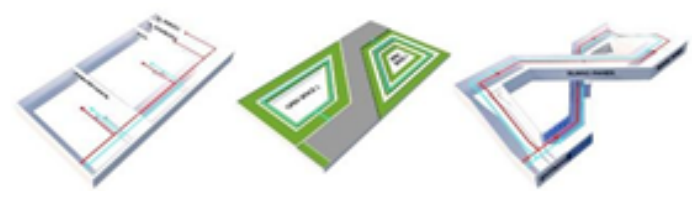

Gambar 12. Konsep Sirkulasi Sumber : penulis

4. Konsep Interior

Konsep interior yang diangkat pada perancangan ini adalah menggunakan metode arsitektur naratif sebagai landasan untuk menguraikan cerita pada museum sehingga pengunjung dapat merasakan dan memahami sejarah van der pijl serta pembangunan Banjarbaru.

Adapun klasifikasi objek berdasar kan wujud benda koleksi pada museum sebagai berikut :

- Dokumen (buku/tulisan dan gambar-gambar karya Van der Pijl)

- Diorama (konservasi bangunan van der pijl)

- Minirama (miniatur rumah tinggal/kantor penataan Kota Banjarbaru)

- Benda grafika (foto/dokumentasi)

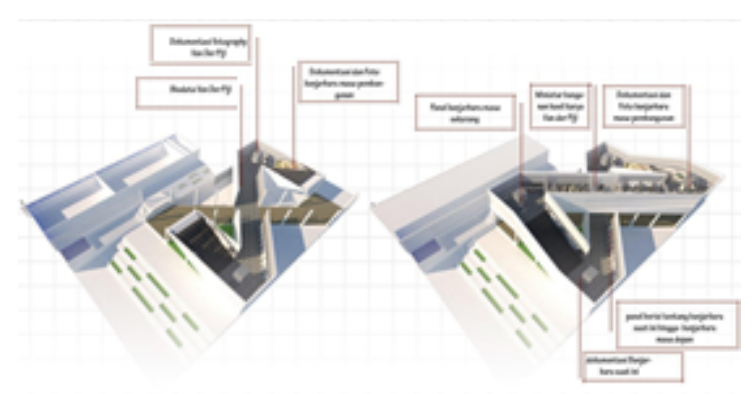

Gambar 13. Konsep Interior Sumber : Penulis

5. Konsep Bentuk Bangunan

Bentuk bangunan diambil dari persegi guna memaksimalkan ruang penunjang dan ruang pengelola pada bagian lantai dasar kemudian di lantai dua dibuat dengan ketinggian yang berbeda-beda pada bagian lantai sebagai ruang semi terbuka selanjutnya pada lantai tiga dibuat lika-liku 
untuk menjelaskan sejarah perjalanan banjarbaru dari awal hingga sekarang.

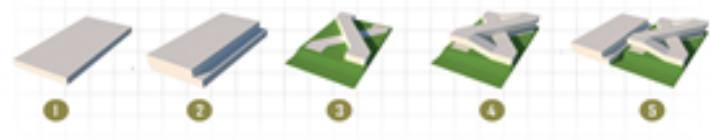

Gambar 14. Konsep Bentuk Bangunan Sumber : Penulis

\section{HASIL}

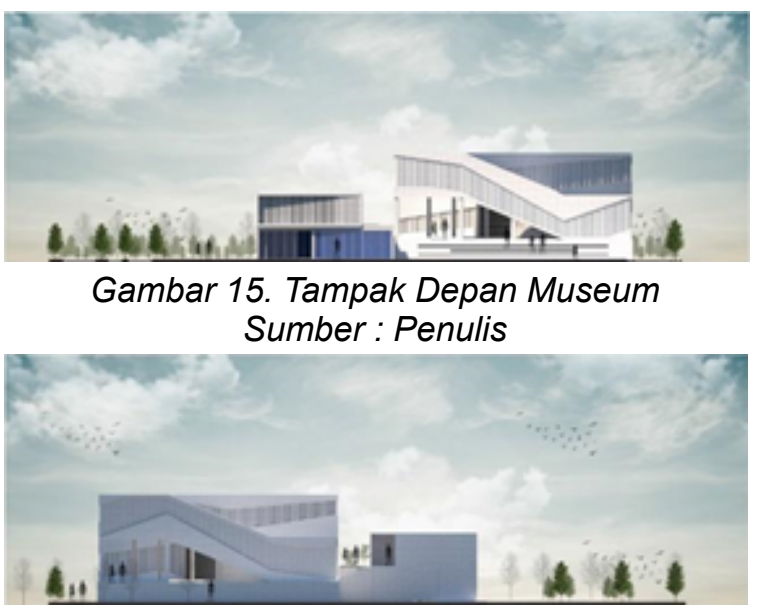

Gambar 16. Tampak Belakang Museum Sumber : penulis

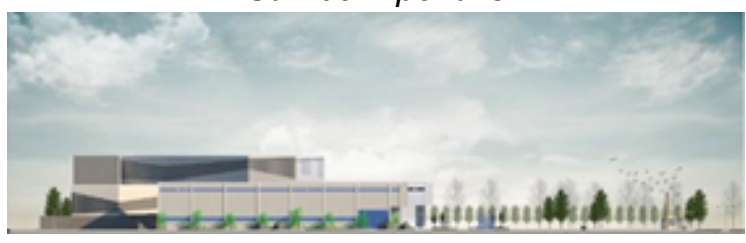

Gambar 17. Tampak Samping Kanan Museum Sumber : Penulis

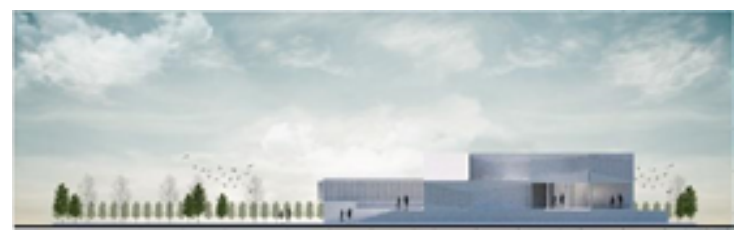

Gambar 18. Tampak Samping Kiri Museum Sumber : Penulis

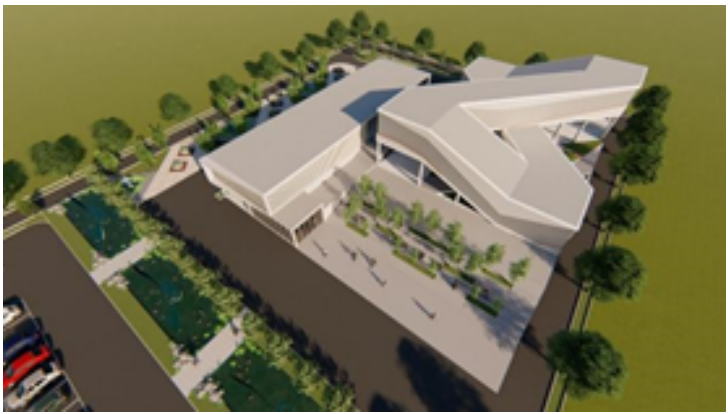

Gambar 22. Perspektif Tampak Atas Museum Sumber : Penulis

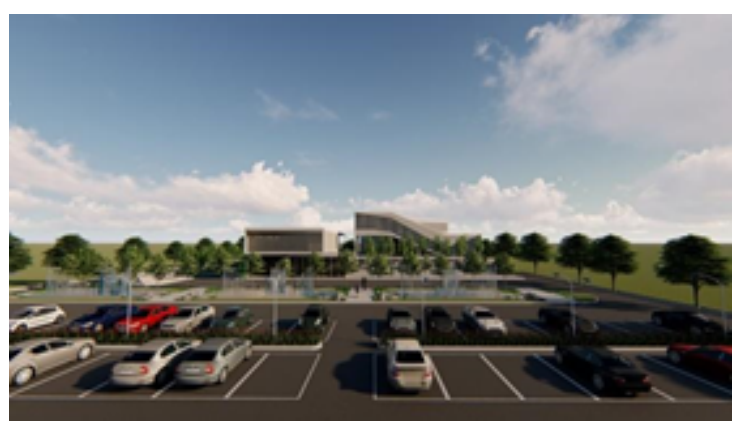

Gambar 19. Perspektif Eksterior Museum Sumber : Penulis

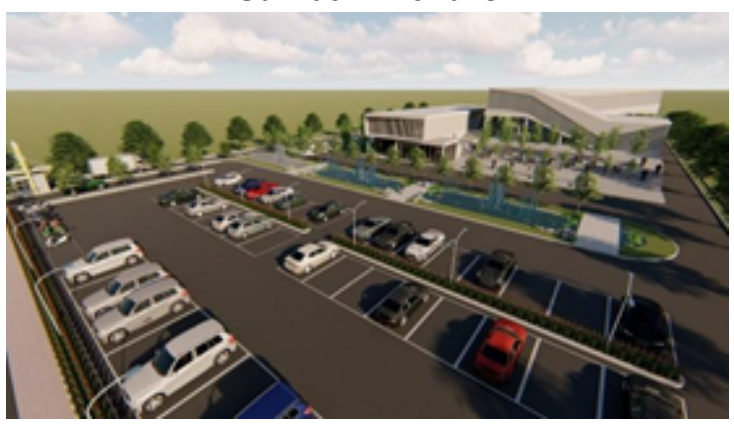

Gambar 20. Perspektif Eksterior Museum Sumber : Penulis

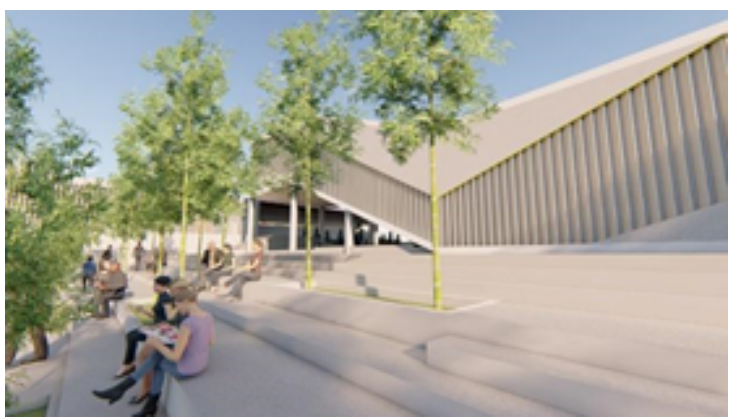

Gambar 21. Perspektif Eksterior Sumber : Penulis 


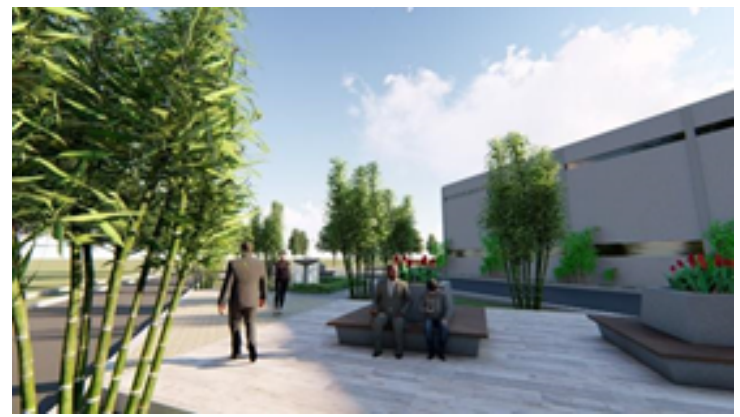

Gambar 22. Perspektif Eksterior Sumber : Penulis

\section{KESIMPULAN}

Perancangan Museum Van der Pijl di Banjarbaru merupakan bentuk upaya menjaga eksistensi peran Van der Pijl dalam proses pembangunan Kota Banjarbaru. Perancangan museum ini bertujuan untuk mengenalkan kembali sosok Van der Pijl agar tetap dikenang sebagai seorang arsitek yang merancang master plan Kota Banjarbaru dan mendesain beberapa bangunan pemerintahan yang ada di Banjarbaru.

Upaya ini dapat dicapai dengan menghadirkan objek pamer yang menjelaskan tentang Van der Pijl dan perkembangan Kota Banjarbaru secara naratif. Bentuk bangunan secara keseluruhan menggambarkan perjalanan Van der Pijl dalam setiap prosesnya membangun Kota Banjarbaru. Pada proses perancangannya bentuk naik turun pada bangunan menggambarkan bentuk usaha dan kerja keras Van der Pijl dalam merancang Kota Banjarbaru.

Perancangan Museum Van der Pijl merupakan rancangan bangunan publik yang berlandaskan edukasi sejarah tentang sosok Van der Pijl. Perancangan ini diharapkan mampu mengenalkan sosok Van der Pijl kepada masyarakat awam dan mampu membangkitkan kenangan tentang peninggalan Van der Pijl. Sehingga proses perkembangan pembangunan Kota Banjarbaru dapat terarsip sebagai salah satu catatan sejarah Kota Banjarbaru dan dapat digunakan sebagai wadah edukasi kepada pemuda pemudi penerus Kota Banjarbaru.

\section{DAFTAR PUSTAKA}

\section{Referensi Buku Dan Jurnal}

ALamsyah, R., (2014) Banjarbaru Sejarah, Pesona, Potensi. Pemerintah Kota Banjarbaru. Banjarbaru

Anha, r P., Dan Aufa, N., (2012) Studi Tata Ruang Kota Rancangan Van der Pijl Kasus : Kota Banjarbaru, Kalimantan Selatan. Biro Penerbit Planologi Undip.

Neufert, E. 1992. Data Arsitek Jilid 1 dan 2. Jakarta;Erlangga.

Neufert, E. 1996. Data Arsitek Jilid 1. Alih Bahasa:Ing Sunarto Tjahjadi. Jakarta:Erlangga.

Neufert, E. 1996. Data Arsitek Jilid 2. Alih Bahasa:Ing Sunarto Tjahjadi. Jakarta:Erlangga

Neufert, E. 2002. Data Arsitek Jilid 2 Edisi 33. Jakarta; Erlangga.

Soekono. (1996), Proyek Pembinaan Permuseuman dan Pengamanan Museum, Jakarta

Egan, D, M., dan Olgyay V., (2001), Architectural Lighting Second Edition. New York: Mcgraw-Hill

Julius, P., (2003), Ruang Interior dan dimensi Manusia . Erlangga

Ching, D.K 2000. Arsitektur: Fungsi dan Bentuk Ruang. Jakarta ; erlangga

Ching, F. D. K. 2004. Desain interior. Alih Bahasa;P. Hanoto Adjie. Jakarta:Erlangga

Huzairin, D, M., Oktaviana, A., dan Mutia, I., (2011), Tipologi dan Morfologi Arsitektur Kolonial Belanda di Banjarbaru. Universitas Lambung Mangkurat Press, September 2011 Jl. H. Hasan Basry, Kayutangi, Banjarmasin 70123 